\title{
Apuntes para una memoria escolar: mi experiencia en el colegio Santa María del Mar'
}

\section{Outlines for a school memory: my experience in Santa María del Mar School}

\author{
Felipe TRILLO ALONSO \\ Profesor de Didáctica en la USC
}

\begin{abstract}
RESUMO: Mediante un estilo biográfico presentase unha escolma de lembranzas sobre a experiencia escolar do autor no Colexio Santa María del Mar (PP. Jesuitas) de A Coruña, destacando tres cursos académicos entre os anos 1972 e 1975. A consideración das mesmas evidencia unha actividade de innovación educativa de alto nivel conforme a parámetros actuais, e sinxelamente extraordinaria naquela época.
\end{abstract}

\begin{abstract}
Through a biographical style, the author presents a selection of memories about his school experience in the Santa María del Mar School (pp. Jesuits) of A Coruña. The article focuses on three academic years (secondary school) between 1972 and 1975. The study of this experience highlights the high level of educational innovation analyzed according to current standards, but not frequent at that time.
\end{abstract}

PALABRAS CHAVE: Relato biográfico, experiencias escolares, educación secundaria, innovación educativa

\footnotetext{
1 Permítaseme relatar aquí como superé el recelo y asumí la idea de escribir este artículo: Fue el 29 de Noviembre de 2004. Como Decano de la Facultad de Ciencias de la Educación de la Universidad de Santiago de Compostela (USC) había organizado unas Jornadas para celebrar el centenario de la creación de la primera cátedra de pedagogía en España, que ocupó Don Manuel Bartolomé Cossío. Fueron dos días de conferencias, que dieron lugar a una publicación (Trillo, F. (ed) (2005): Las Ciencias de la Educación del ayer al mañana Universidad de Santiago de Compostela) impartidas por destacados catedráticos de pedagogía. Aquella noche, nos reunimos a cenar invitados por mi colega Mar Lorenzo, por entonces Vicerrectora de Estudiantes de la USC. Hablamos de muchas cosas, pero un tiempo muy largo lo dedicamos a contar nuestras respectivas experiencias escolares, bien distintas por muchos motivos como el de la diferencia de edad. Gonzalo Vázquez Gómez de la Universidad Complutense, José Luís Rodríguez Dieguez, Javier Tejedor Tejedor y José Ortega Esteban de la Universidad de Salamanca, Sebastián Rodríguez Espinar de la Universidad de Barcelona, y Antonio Viñao Frago de la Universidad de Murcia. Mucho saber reunido: Teoría e Historia de la Educación, Metodología de la Investigación y Orientación Educativa, Pedagogía Social y Didáctica. Resultó una tertulia muy agradable: la última en la que la mayoría pudimos disfrutar de la compañía entrañable de José Luís (q.e.p.d). En aquel marco, recuerdo que la singular atención que me prestó el historiador del grupo, el Profesor Viñao, me hizo considerar que tal vez mereciese la pena poner en negro sobre blanco mis recuerdos. Han pasado cinco años.
} 
KEY WORDS: Biographical narrative, school experiences, secondary education, educational innovation

PALABRAS CHAVE: Relato biográfico, experiencias escolares, educación secundaria, innovación educativa

KEY WORDS: Biographical narrative, school experiences, secondary education, educational innovation

Me refiero al Santa María del Mar, de los Jesuitas, en A Coruña, que en mi opinión se merece un lugar destacado en la historia de la educación en España.

El análisis de sus propuestas didácticas y, especialmente, de los valores educativos que lo caracterizaron en manifiesto contraste con las coordenadas sociales y culturales de la época (1965-1975), representó a mi juicio una experiencia de innovación educativa digna de ser recordada y emulada.

Como profesor de didáctica y estudioso de la pedagogía creo que podría realizar ese análisis -lo he hecho muchas veces-, pero como puede sucederle a un cirujano impelido a operar a su padre, me tiembla el pulso cada vez que me aproximo a ese cuerpo con el bisturí del análisis curricular.

En ese sentido, también soy (pese a lo años transcurridos) ex -alumno de ese colegio, y cuando lo evoco, aún sin lograr establecer hasta qué punto o de qué modo es así, no puedo evitar reconocerme como deudor suyo; y eso lo trastoca todo (1). En consecuencia, lo que sigue es un artículo esencialmente biográfico, más atento al relato personal sobre algunas actuaciones y personas.

Siendo así, he preferido que los recuerdos se desgranen sin que se ciñan a un orden preconcebido que, sin duda, habría contribuido a su sistematización pero que, al mismo tiempo, temí que pudiera cercenar la confiada espontaneidad de mi memoria. Inevitablemente selectiva, desde luego, pues no todos lo vivimos, percibimos ni aprovechamos igual.

Fuere como fuese, sí importa el hecho de que todo esto ocurrió especialmente, al menos para mí, entre 1972 y 1975: desde 5º de Bachillerato a C.O.U, entre los 14 y los 17 años, una edad muy impresionable, en una época singular, la de los último años del gobierno de Franco.

\section{Las experiencias}

El arte de amar y El miedo a la libertad, ambos de Erich Fromm, fueron dos libros de referencia jen 1972!, en el marco de una asignatura que se llamaba Formación Humana. Una escuela de introspección, de reflexión crítica sobre nosotros, nuestro entorno y sobre nosotros en nuestro entorno. Y una aproximación a la sexualidad no meramente orgánica o genital, sino emocional y ética, y por lo mismo potencial y preferiblemente consciente y autorregulada. Seguro que no lo dije entonces con estas palabras pero sin duda fue allí donde supe que eso que llaman hacer el amor muchas veces no tiene nada que ver con 
amar, y que esto es mejor. Y por si no fuera suficiente, nos llevaron al cine forum (en la Universidad Laboral), a ver nada más y nada menos que Hiroshima Mon Amour (de Alain Resnais, 1959). Insisto, jera 1972! Y así, desde entonces hasta COU vinieron otros libros, aunque ya para los iniciados, esta vez de Wilheim Reich, ambos prohibidos: La Revolución sexual y La función del Orgasmo; en suma, Freud y Marx reunidos, en el Bachillerato, durante el régimen de Franco.

Que yo recuerde, el profesor Manuel Romero, el Padre Joaquín García de Dios y en lo del cine el Padre Manuel Mazón estaban detrás: sospechaba entonces y confirmo ahora que, sin duda, entendieron bien que lo que necesitábamos era desarrollar un pensamiento reflexivo y una ética personal.

La asignatura de Historia del Pensamiento y de la Cultura, redenominación de la antigua Historia del Arte, nos dejó más bien huérfanos de conocimientos artísticos. Poca pintura, poca arquitectura, en contraste con lo que estudiaban nuestros amigos de otros colegios. A cambio, nos abrimos al Mundo: La Introducción a la Sociología de Bottomore, nos descubría el sistema de castas de la India (quizás para evitar hablar de clases ...), pero a partir de ahí podíamos extraer similares conclusiones sobre la justicia social, o mejor, sobre la injusticia. Y si a eso le sumamos, un trabajo sobre la discriminación racial con los gitanos en España asociado a otro sobre la rebelión social del Black Power y de Malcon $\mathrm{X}$ en los Estados Unidos, aquello supuso nuestro despertar a una realidad mucho más conflictiva de lo que pretendía el orden establecido y que por razones de procedencia familiar nos estaba vedada a la mayoría. Los iniciados, así, pronto accedimos a la Historia de España de Pierre Vilar, otro libro prohibido, o a las ideas sobre el "comunismo básico" de Lewis Munford. Y por si fuera poco, dos experiencias directas e intensas: La primera, un trabajo de campo en la villa de Celanova junto a los chicos de la ciudad de los muchachos del Padre Villa, por entonces alojados en el Monasterio de San Rosendo; adolescentes como nosotros pero con historias personales y familiares tan diferentes de las nuestras. $Y$ la segunda, dos días de estancia en el Pozo del Tío Raimundo en Madrid, en la Escuela Profesional Primero de Mayo, dirigida por un jesuita, y muy próxima a la vivienda de dos referentes de la Orden, el Padre José María Díez Alegría y el Padre José María Llanos, y en donde tuve oportunidad de escuchar a un chico más joven que yo lo siguiente: <<Aquí no sólo nos enseñan un oficio, también nos dan un lenguaje con el que podemos denominar a las cosas por su nombre, y tomar conciencia sobre como están, y por ese motivo resultamos peligrosos y, con frecuencia, nos cierran las instalaciones, pero entonces nosotros las escalamos y nos encerramos dentro y trabajamos aunque no nos dejen >>.

El Profesor Jose Luís Vázquez Dequidt y el Padre Manuel Mazón estaban detrás de todo esto: sospechaba entonces y confirmo ahora que, sin duda, entendieron que necesitábamos un baño de realismo social como germen imprescindible para cualquier futuro compromiso político (y/o cristiano).

Jarcha, Serrat musicando a Machado, Paco Ibáñez en el Olimpia. ¡Discos en clase!, nuestros compañeros de otros colegios no daban crédito. $Y$ después aquellos libros que no tenían nada que ver con los hermanos Quintero, pongo por caso. Tiempo de Silencio 
de Martín Santos. El Jarama de Sanchez Ferlosio. Requiem por un campesino español, de Ramón J. Sender. No eran libros al uso para gente bien pensante. Y en el horizonte inmediato, los iberoamericanos. $Y$ claro que a algunos ya nos gustaba leer, pero hay muchas maneras de hacerlo.

El Profesor Antonio León, al inicio, y los profesores María Pérez y Fernando Pariente, más tarde, estaban detrás: sospechaba entonces y confirmo ahora que, sin duda, entendieron que necesitábamos descubrir a la literatura como algo más que un ejercicio de estilo o una forma de evasión, que necesitábamos descubrir la fuerza emancipadora de la palabra.

Todos los deportes, en fin, muchos (fútbol, baloncesto, balonmano, voleibol, jockey, esgrima, ajedrez), y atletismo (cien metros, mil metros, vallas, altura, longitud), y gimnasia. Toda una tarde semanal de jornada deportiva en unas instalaciones casi profesionales para la época. Y el aula específica de trabajos manuales. Y el aula de música para las audiciones. Y el laboratorio de idiomas, con sus rudimentarios magnetofones, donde reforzar la enseñanza de profesores "nativos" (así llamados). Una oferta y una disponibilidad de recursos más que notable.

La "cogestión", no era un trastorno digestivo, sino que, junto a la insistencia en la creatividad, eran ambas dos ideas que -creo- había traído de USA el Padre Jesús Garrido. No dieron quizás todo el juego que podrían haber dado pero sin duda nos hicieron pensar:

La primera, por su parte, sugería la posibilidad de participar del gobierno del colegio, de elegir democráticamente a nuestros representantes (en un país donde eso no existía). Nunca funcionó bien que yo recuerde, pero era un tema recurrente que nos presentaba una manera distinta de estar en sociedad, no subordinada, corresponsable. ¿Nos estaban preparando para otro orden social y político? Aún faltaban tres años y varios meses para votar la Constitución, algo que, supongo, no mucha gente preveía. Pero quizás sí, y por eso "la FEN", la asignatura de Formación del Espíritu Nacional resultó en nuestro caso tan descafeinada, tan desideologizada y tan carente de fervor patriótico a diferencia de lo que todavía ocurría en algunos colegios próximos.

La segunda tenía que ver con aprender a opinar, a construir una idea nueva y personal frente a la mera memorización y reproducción. No estaba mal. Nos proporcionó, sin duda, otras competencias, como se diría hoy. Aunque creo que de aquello vino la recomendación de que no nos presentáramos a la (memorística) Reválida de Sexto, que justo en aquel momento se había establecido como voluntaria en vez de obligatoria ... En términos actuales, quizás nosotros hubiéramos puntuado en el Informe Pisa mucho mejor que la mayoría, incluso hoy en día.

Había (todavía hay) una revista, Padres y Maestros, inicialmente asociada al Colegio y que se distribuía entre las familias antes de editarse a nivel nacional e internacional. Revista que alternativamente dirigida, creo, por Jesús Garrido y Joaquín García de Dios, representó una experiencia pionera en la formación de profesores y como escuela de padres (a distancia). Actividades ambas que el Colegio y/o la Revista, más tarde, también 
promovían de manera presencial para propios y extraños, adelantándose una vez más a su tiempo. Trabajaban allí, Dolores Vázquez como Secretaria -conmigo siempre exquisitamente amable-, y como Gerente Fernando Garrido -entrañablemente cordial-, que fue además el artífice de otra iniciativa pionera: las páginas de La Voz de la Escuela en el diario La Voz de Galicia. Buena gente.

En cuanto a la religión. A ver, era un colegio de curas. Pero, si empiezo por decir que siquiera de puertas para adentro lo de la masturbación se había despenalizado, y que asistir a misa era un acto voluntario y no farisaicamente obligado, se confirma la idea de que algunos cánones sobre lo que debía ser una correcta conducta cristiana estaban cambiando; al menos a la vista de un adolescente. Frente a las normas destacaban las esencias. Lo que importaba: no era el pecado sino el perdón, no era la confesión sino el arrepentimiento y el ánimo de enmienda, no era el ritual sino la comunión como la común unión con Dios, no era el rezo sino la oración como diálogo, no era el cumplimiento como cumplo y miento sino el sentido de la transcendencia, no era la ortodoxia sino el ecumenismo, no era el temor de Dios sino el amor de y a Dios. Muchísimos años antes de que se hablase abiertamente de eso, nosotros, bajo la apariencia formal de una clase de religión, teníamos también algo muy parecido a un seminario de religiones comparadas.

El Padre Joaquín García de Dios, estaba detrás: sospechaba entonces y confirmo ahora que, sin duda, entendió que lo que necesitábamos no era empaparnos de doctrina sino nacer a la fe, como una experiencia íntima pero solidariamente compartida, como un acto de confianza en lo desconocido jamás como una transacción. Debo decir que mucho me temo que no tuvo un gran éxito con la mayoría de mis compañeros, pero al menos por lo que a mí respecta acertó plenamente.

Era, claro, un colegio sólo de chicos todavía, pero faltaba poco para que fuera mixto. De hecho COU ya lo era. Estaban dando los pasos para reconocer formalmente como natural lo que es sencillamente natural; le llamaron coeducación, pero es llanamente convivencia: la mejor manera de superar cualquier discriminación sin que hagan falta grandilocuentes discursos. No pudimos aprovechar más que un curso esa circunstancia de tener a chicas por compañeras, pero creo que aprendimos mucho: entre otras cosas, que nos daban sopas con honda. Los cimientos para el respeto mutuo se habían forjado y, a la par, sepultado para siempre en el hormigón cualesquiera resabios machistas.

Y durante todo ese tiempo funcionaron, anticipándose varios años a la extensión de su uso, los mal llamados tests psicológicos, que realizaba el Padre Toscano, y a partir de ellos los estudios sobre nuestra personalidad que comentábamos con nuestros tutores quienes, más bien que mal ejercían realmente sus funciones como tales, y en cuyo marco las acciones de orientación profesional cobraban plenamente sentido.

Y luego están "los amigos del colegio", ese tesoro de vivencias compartidas. Cada uno siguió su camino y a muchos hace años que no les he vuelto a ver: Rolando, Norberto, Uribe, Tyssen, Otero, Aymerich, Corrochano, Veiga Villegas, los Esteban, Herrero, los Cobián, Comí, Uriarte, Figueroa, Caridad, Recuna, Manovel, López Lens, Pardavila, Luengo, 
López Iglesias, Andrés Vázquez, Diego, Tonino, María Debén, Mar, Malena, Beatriz, Mariles, Loli, Dolores, Amalia, Socorro, Teresa, Cocó, Miriam, Isabel, Eugenia... Pero otros aún están ahí y para siempre: Tomás Fábregas, Puri, Victoria, Elisa, Tere y Cándido.

No sé, yo creo que no estuvo nada mal.

Naturalmente, todos estos hechos tuvieron lugar en espacios concretos que estaban habitados por personas.

\section{Los espacios}

Como si de una película se tratase es posible identificar los escenarios:

El colegio de los Jesuitas en sus albores, en el curso 1962/63 en el que me matriculé por primera vez, ubicado en el edificio denominado de "los coscas" (nunca supe por qué), en la coruñesa Avenida de Juana de Vega, al lado de la Iglesia de los Jesuitas, y a la que podíamos acceder (para ir al coro y a la preparación para la primera comunión) a través de una pequeña puerta al final de un patio que, con cuatro años, recuerdo inmenso; y que, por curiosa asociación, relaciono siempre con los diminutos y ácidos caramelos kengo que el Padre Enrique von Riedt nos lanzaba para feliz alborozo de la chiquillería.

Y el colegio Santa María del Mar, más tarde, ya en Las Jubias, donde poco a poco, desbrozando el monte (en su sentido literal), el colegio se ubicó definitivamente frente a la ría, mediante una obra arquitectónica ingente y singular (concebida por Miguel Fisac y dirigida por Andrés Fernández Albalat), y de la que algunos llegamos a sentirnos poco menos que colonos.

Metafóricamente, además, el cambio de ubicación representó asimismo un cambio radical de orientación educativa. Es como si los respectivos horizontes de ambos edificios la determinasen: la primera, enclaustrada en el pasado, y la segunda, abierta a un dilatado paisaje de futuro.

\section{Las personas}

Y sí, como si de una película se tratase cabe destacar también a los personajes toda vez que, desde mi perspectiva-y en esto soy radicalmente subjetivo-, algunos asumieron papeles estelares, otros ejercieron un evidente protagonismo, y muchos desempeñaron un papel secundario pero imprescindible. Deseo mencionarlos, aún a riesgo de olvidar a más de uno y resultar injusto (mal que bien, mejor serlo con una docena que con todos). En esta relación obvío también, por caridad, a unos pocos de los que no guardo tan grato recuerdo (sirva el eufemismo). Es sólo una mención, nada más, seguida a veces de un brochazo de memoria, que tampoco hace justicia a sus biografías, pero que pretende ser afectuosa.

Primero "los curas".

Los de la vieja escuela: Enrique von Riedt Meana, el Director, supongo que el fundador, que me "examinó", o eso creía yo, para entrar al colegio en 1962. Su ayudante, el 
Hermano Ramos, del que no supe más, pero al que siempre recuerdo cuando veo una película en el que un cura juega al fútbol levantándose la sotana. El Padre Usallán, que en la asignatura de historia "Universal" organizaba concursos (emulando el de "Cesta y Puntos") mediante los que avanzábamos o retrocedíamos puestos en el orden de los pupitres según acertáramos o no con nuestras respuestas.

Y a continuación, "los modernos"; no se quién llegó antes, o si vinieron juntos: el Padre Joaquín García de Dios, al que me referiré después; el Padre Jesús Garrido, que se había formado en USA lo que le confería un caché especial, siempre con sus maneras elegantes y su condescendiente sonrisa. Ambos, fueron los auténticos artífices del Colegio que evoco, pues supieron crear un equipo capaz de desarrollar un proyecto educativo coherente y, sobre todo, esperanzador para la época. Al mismo tiempo que ellos o un poco más tarde llegaron al colegio: el atlético Padre Ball, con sus inquietantes gafas oscuras; el Padre Marcial, que se ocupaba de las finanzas, y que era absolutamente emocional, pues tanto pasaba de un afecto apabullante a un genio aterrador, y de quien se contaba que era uno de los personajes (creo que el protagonista) de una célebre novela para adolescentes, La vida sale al encuentro, que causaba furor entre nosotros y de la que era autor otro jesuita, Martín Vigil; el Padre Toscano, éste de sonrisa enigmática, de caminar pausado, y al que por ocuparse de los informes psicológicos de cada uno de nosotros le atribuíamos un conocimiento sobre nuestra intimidad superior al que nosotros mismos teníamos; el Padre Corral, temperamental, jovial, a veces sarcástico, que daba capones con un silbato, siempre presumiendo de su ,experiencia en California (envidiable), y que resulto ser un supervisor sencillamente excepcional del mítico viaje de COU (por Europa, 21 días, en el autobús de Manolo Navajas); el Padre Mazón, que según tuviera el día resultaba severo o bonachón, y que -creo- se aburría más que nosotros con sus lecciones de griego 0 de filosofía por lo que, a través de ellas, intentaba animarse y formarnos con sus lecciones sociales, lamentablemente poco aprovechadas por quienes, aunque apuntásemos maneras, aún vivíamos más en la inconsciencia y la frivolidad; el Padre Barrios, encerrado en sí mismo, que no me dio clase por lo que sólo le recuerdo cumpliendo estoicamente (y cierta desgana) con el aburrido quehacer de corregirnos en los patios y pasillos, y a quien acompañé en su funeral hace apenas unos meses. En fin, esos fueron "mis curas".

Y después estaban los profesores: la Señorita Trini en primer grado (¿dónde se van los maestros que nos enseñaron las primeras letras?); Alberto Freire (con su huerta escolar y del que atesoro mil anécdotas ...); el alto y paciente Tomás; el bajo y agobiado Pampín; Miguel Biurrum (que tanto me hizo sufrir con el plinton); el Sr. Murias (anotando nuestro mal comportamiento con "puntitos"); Mr. Mack, el australiano, siempre sonriente y medio cómplice; Fernando Crespo, siempre sosegado y erguido, que era un referente esencial en Primaria; Francisco Parga, descubriéndonos, un tanto escéptico, el placer de aprender a escuchar música clásica; Antonio León, vocacional mientras pudo y con el que, en una experiencia inédita, quedamos algún sábado para ir al cine a ver alguna película que nos recomendaba. Y después: José Luis Medal, cálido y discreto; Antonio Luengo, socarrón, prematuramente fallecido y del que inventábamos épicos tortazos relacionados con su antigua condición de lanzador de martillo; Moncho Nuñez, que por ir yo por letras no pude 
disfrutar pero de quien mis amigos contaban maravillas y que, desde hace años, es el director, fundador y referente de la Casa de las Ciencias, la Casa del Hombre y la Casa de los Peces de A Coruña; Fernando Pariente, siempre próximo y accesible, descubriéndonos la posibilidad de conocernos a través de la literatura; María Pérez, que nos acercó como pocos a la poesía; Romero, con su vocación por educarnos y del que me acuerdo siempre cuando veo al maestro protagonista de la película Los chicos del coro; y, por fin, Yayo (Eduardo Hernández), abierto las veinticuatro horas, también en su casa, iconoclasta, heterodoxo, un tanto anarquista, que nos inició a algunos en la vía del cuestionarlo todo empezando por nosotros mismos.

Faltan muchos, ya lo se.

En cualquier caso, de entre todos, permítaseme destacar a Joaquín García de Dios. Por su manera de ser, sé que él preferiría censurar este apartado. Por su manera de ser, sé que se reprimiría y me dejaría hacer. Siempre lo hizo. Quede claro que no lo escribo para engordar su ego, al contrario, lo hago para presumir yo de haber tenido la suerte de contar siquiera con un Maestro. Y es que hay que situarse: en el contexto de una España donde cualquiera se creía en el deber de corregirte y de atarte en corto, Joaquín siempre respetó nuestro derecho a equivocarnos, y a aprender en consecuencia. Conmigo ha sido siempre acogedor, cálido, comprensivo, de ese tipo de comprensión que te hace sentir que el otro se ha puesto en tu lugar; paciente, a medio e incluso hasta a largo plazo, transmitiéndote una confianza en tus posibilidades muy superior a la que uno mismo estaría dispuesto a otorgarse, y haciéndolo especialmente y sin reconvención alguna en esos momentos de duda, de desconcierto, de inseguridad y de rendición; abriendo en suma ventanas cuando las puertas se cierran.

Cuando pienso en él siempre acudo a la misma frase: "Tenemos por maestro a quien ha remediado nuestra ignorancia con su saber, a quien ha formado nuestro gusto o despertado nuestro juicio, a quien nos ha introducido en nuestra propia vida intelectual, a quien -en suma- debemos todo, parte 0 algo de nuestra formación y de nuestra información; a quien ha sido mayor que nosotros y ha hecho de su superioridad ejemplaridad; a alguien de quien nos hemos nutrido y sin cuyo alimento u operación no seríamos quien somos. Alguien, en fin, cuya obra somos en alguna medida"2.

Hoy somos amigos (pese a la distancia), y eso me transmite un consuelo especial.

En fin, ha salido biográfico, como amenazaba. Es sólo una anécdota, lo sé. Pero es que me apetecía contarla.

HUBO UNA VEZ UN COLEGIO... que más de treinta años después, late todavía en mi memoria y me enternece.

2 No recuerdo la fuente, creo que es del Dr. Gregorio Marañón refiriéndose a Don Santiago Ramón y Cajal; nada menos. 